\title{
Investigation and Analysis of Satisfaction of Rail Transit Transfer Station Facilities in Changchun
}

\author{
Chuansheng Zhou, Lijie Xie, Zhen Lian, Meng Du, Xiaoyang Li, Pinchao Meng, Sanzhi Shi* \\ Science School, Changchun University of Science and Technology, Changchun, China \\ Email: "shisanzhissz@163.com
}

Received 15 July 2015; accepted 27 December 2015; published 30 December 2015

Copyright (C) 2015 by authors and Scientific Research Publishing Inc.

This work is licensed under the Creative Commons Attribution International License (CC BY).

http://creativecommons.org/licenses/by/4.0/

c) (i) Open Access

\begin{abstract}
The comfort satisfaction of basic facilities of the rail transit transfer station will influence pedestrian choice of vehicle. Aiming at the problem of traffic jams in Changchun in China, we designed a satisfaction questionnaire to investigate the factors which might affect the pedestrian satisfaction in rail transit transfer station in Changchun. By using the statistical methods, including correlation analysis, factor analysis and comparative analysis of satisfaction and importance, we analyzed the survey data, and get the results of analysis. Some suggestions for rail transit transfer station based on the results are given.
\end{abstract}

\section{Keywords}

Rail Transit Transfer Station, Satisfaction, Questionnaire, Factorial Analysis, Correlation Analysis, Comparative Analysis

\section{Introduction}

With the development of society, the phenomenon of urban traffic is becoming serious day by day. City rail transit transfer stations play an important role in public Transport. It is necessary for us to learn about whether citizens satisfied with city rail transit transfer station. Customer satisfaction models ACSI (American Customer Satisfaction Index) are widely used by people who make research about satisfaction which also is a classical model of research satisfaction made by Fornell et al. (1996) [1].

There are many people study satisfaction. Joan L. Giese (2000) [2] propose a framework for developing context-specific definitions of consumer satisfaction. Amy K. Smith et al. (1999) [3] develop a model of customer

\footnotetext{
*Corresponding author.
}

How to cite this paper: Zhou, C.S., Xie, L.J., Lian, Z., Du, M., Li, X.Y., Meng, P.C. and Shi, S.Z. (2015) Investigation and Analysis of Satisfaction of Rail Transit Transfer Station Facilities in Changchun. Applied Mathematics, 6, 2311-2318. 
satisfaction with service failure/recovery encounters. Morgan, N. J. et al. (1996) [4] investigate a potential moderator of the relationship between affect and cognition and consumer satisfaction/dissatisfaction.

Many researchers also study transportation. Kretz, T. (2007) [5] study Pedestrian Traffic by using simulation and experiments. Dannmen, W. (2004) [6] describes the development of a new type of simulation tool for the assessment of designs of public transport facilities. Griffin, Kenneth W. (2004) [7] write the book which covers the essentials of designing transit facilities.

In this paper we use ACSI models to construct the pedestrian satisfaction model in transportation. We designed the satisfaction questionnaire to investigate the factors which might affect the pedestrian satisfaction in rail transit transfer station. By using the statistical methods, including correlation analysis, factor analysis and comparative analysis of satisfaction and importance, we analyze the data of survey. As a result, we propose some suggestions about the rail transit transfer station.

\section{Rail Line Planning in Changchun}

In China, Changchun rapid rail transit network planning was completed in 2002, and was revised in 2009. The planning include 7 subway and light rail lines, the five subway lines (line 1, line 2, line 5, line 6, line 7), two light rail lines (line 3, line 4). Total length of the lines is $253.9 \mathrm{~km}$. Line 3 and line 4 are in used, total length $48.3 \mathrm{~km}$.

\section{Questionnaire Investigation}

Over the past year, aiming at the problem of traffic jams in Changchun, our research group investigate the factors which might influence on pedestrian satisfaction of rail transfer station in Changchun. According to Xu's (2009) [8] Methods of Social Investigation and Research, we design and issue questionnaires two times. In the first time we issued 300 questionnaires in July 2014, and get the data of pedestrian satisfaction of Changchun rail transfer Center. We used the method of analytic hierarchy to analysis the satisfaction. See Zhou et al. (2015) [9]. In the second time, we issued 500 questionnaires, 475 copies valid (invalid for missing or fill out too much). On January 13, 2015 issued 350 questionnaires in Changchun rail transfer center, 331 valid. On March 21, 2015 issued 150 copies in Linhe Street transfer station, 144 valid. Figure 1 shows pictures in Changchun rail transfer center.

The second questionnaire consists of 15 problems, 5 problems are personal information, others are satisfaction, including the comfort satisfaction of various facilities, service attitude satisfaction of the station staff. Such as, "Transfer station environment", "Lighting and the heating system in transfer station", "Escalator, chairs and trash can in transfer station", and so on.

\section{The Statistical Analysis of the Survey Results}

For convenience, we use the letters $A_{1}, A_{2}, A_{3}, A_{4}, A_{5}, A_{6}, A_{7}, A_{8}, A_{9}$ and $A_{10}$ to denote satisfaction of facilities, respectively. That is
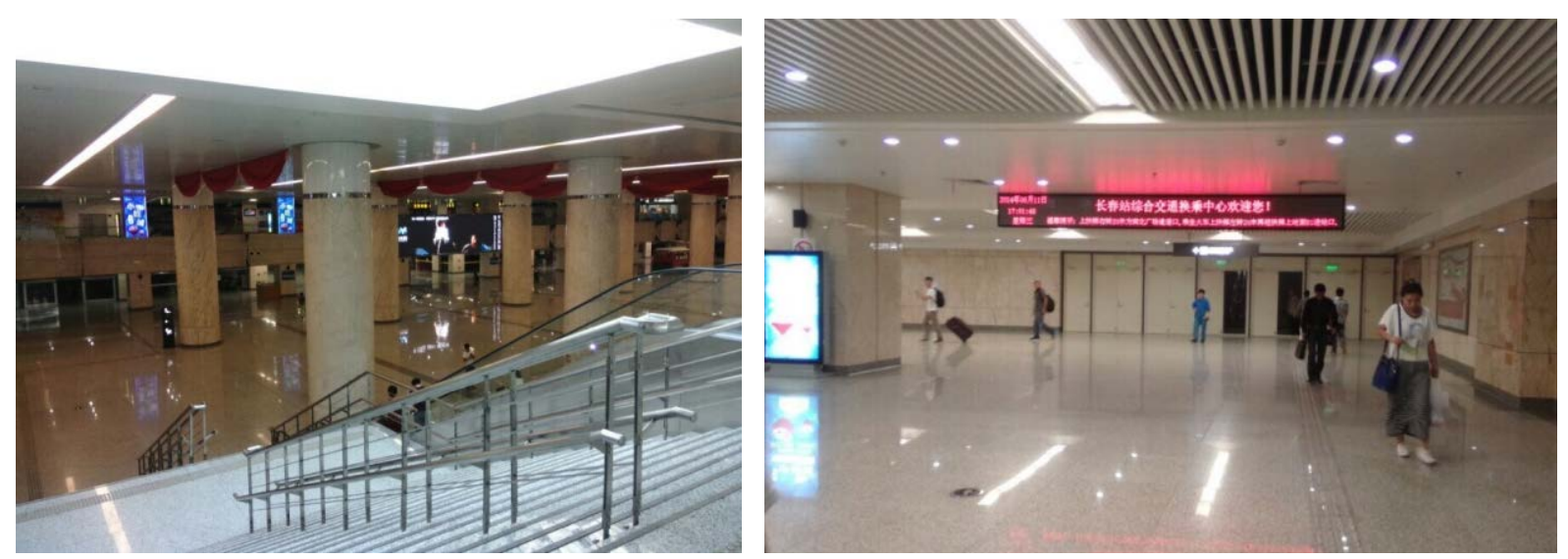

Figure 1. Interior pictures in Changchun rail transfer center. 
$A_{1}$ - Transfer station environment,

$A_{2}$ - Lighting and the heating system in transfer station,

$A_{3}$-Escalator, chairs and trash can in transfer station,

$\mathrm{A}_{4}$ - Crowded degree in transfer station,

$A_{5}$ - Security facilities in transfer station,

$A_{6}$ - Pull in and out station time,

$A_{7}$-Numbers of ticket windows and check-in path,

$A_{8}$ - Number of vehicles shifts per day,

$A_{9}$-Information provided by transfer station,

$A_{10}$ - Service attitude of the station staff.

In this paper, we used the statistical methods, including correlation analysis, factor analysis, and comparative analysis of satisfaction and importance to analyze the survey data. The statistical software we used is SPSS.

Correlation analysis is able to obtain the correlation of two variables, and to determine whether the correlation between these variables is statistically significant. In section 4.1, we analyzed the relevance within two transfer station facilities, and found correlation between the various facilities satisfaction.

Factor analysis in multivariate statistics is a kind of dimension reduction. We used factor analysis to simplifying factors, with less common factors to reflect the complex phenomena. In section 4.2, we tried to find the main influencing factors of the two rail transfer station, respectively.

In section 3.3, we compared the relationship between satisfaction and importance in rail transfer station facilities.

\subsection{Correlation Analysis}

Pearson correlation coefficient, Kendall correlation coefficient and Spearman correlation coefficient are widely used. We use Pearson correlation coefficient to analyze the correlation and its formula is as follow:

$$
r=\frac{\sum\left(x_{i}-\bar{x}\right)\left(y_{i}-\bar{y}\right)}{\sqrt{\sum\left(x_{i}-\bar{x}\right)^{2} \sum\left(y_{i}-\bar{y}\right)^{2}}},
$$

where $r \in[-1,1], r>0$ means the positive correlation, $r<0$ means the negative correlation. $|r|$ is closer 1 , the correlation is stronger. We used the method of Pearson correlation coefficients in SPSS. The results are shown in Table 1.

It can be seen that the correlation coefficient of "Security facilities in transfer station" and "Numbers of ticket windows and check-in path" is maximum, 0.996. The second is the correlation coefficient of "Security facilities in transfer station" and "Pull in and out station time", 0.995. The minimum is the correlation coefficient of "Crowded degree in transfer station" and "Number of vehicles shifts per day", 0.780. In addition, we analyzed

Table 1. The results of correlation analysis in 475 questionnaires.

\begin{tabular}{ccccccccccccc}
\hline & $A_{1}$ & $A_{2}$ & $A_{3}$ & $A_{4}$ & $A_{5}$ & $A_{6}$ & $A_{7}$ & $A_{8}$ & $A_{9}$ & $A_{10}$ \\
\hline$A_{1}$ & 1 & 0.971 & 0.983 & 0.922 & 0.970 & 0.975 & 0.970 & 0.938 & 0.948 & 0.898 \\
$A_{2}$ & 0.971 & 1 & 0.957 & 0.830 & 0.988 & 0.993 & 0.978 & 0.973 & 0.965 & 0.920 \\
$A_{3}$ & 0.983 & 0.957 & 1 & 0.915 & 0.961 & 0.950 & 0.949 & 0.883 & 0.915 & 0.852 \\
$A_{4}$ & 0.922 & 0.830 & 0.915 & 1 & 0.882 & 0.867 & 0.900 & 0.780 & 0.880 & 0.854 \\
$A_{5}$ & 0.970 & 0.988 & 0.961 & 0.882 & 1 & 0.995 & 0.996 & 0.953 & 0.987 & 0.954 \\
$A_{6}$ & 0.975 & 0.993 & 0.950 & 0.867 & 0.995 & 1 & 0.994 & 0.978 & 0.988 & 0.957 \\
$A_{7}$ & 0.970 & 0.978 & 0.949 & 0.900 & 0.996 & 0.994 & 1 & 0.957 & 0.995 & 0.972 \\
$A_{8}$ & 0.938 & 0.973 & 0.883 & 0.780 & 0.953 & 0.978 & 0.957 & 1 & 0.961 & 0.936 \\
$A_{9}$ & 0.948 & 0.965 & 0.915 & 0.880 & 0.987 & 0.988 & 0.995 & 0.961 & 1 & 0.989 \\
$A_{10}$ & 0.898 & 0.920 & 0.852 & 0.854 & 0.954 & 0.957 & 0.972 & 0.936 & 0.989 & 1 \\
\hline
\end{tabular}


Changchun rail transfer center and Linhe street transfer station, respectively. The correlation coefficients of Changchun rail transfer center are roughly the same with the total data. Linhe Street is slightly different. The maximum correlation coefficient is "Number of vehicles shifts per day" and "Pull in and out station time", 0.997. The second is "Number of vehicles shifts per day" and "Numbers of ticket windows and check-in path", 0.982. The minimum is "Crowded degree in transfer station" and "Information provided by transfer station", 0.718. The fact is that line 3 and line 4 transfer channel is very long in Linhe street transfer station. The results of the survey reflected in that channel length of the transfer station affects the degree of correlation between the various facilities.

\subsection{Factor Analysis}

Factor analysis usually needs to do non-dimensionalization, that is data normalization. It can keep the relative stability of original values which can also bring a lot of convenience. The formula is as follow:

$$
x_{i j}=\frac{x_{i j}-\overline{x_{j}}}{\sqrt{\operatorname{var}\left(x_{j}\right)}}(i=1,2, \cdots, n ; j=1,2, \cdots, k),
$$

where $\overline{x_{j}}$ and $\sqrt{\operatorname{var}\left(x_{j}\right)}$ represent mean and standard deviation of the $j$ th variable.

Factor analysis extracts common factors from the variables and finds the correlation between each variable. Our purpose is to avoid bias caused by the correlation between the variable. Using factor analysis needs to a strong correlation of these variables. In general, it is not suitable for factor analysis when the majority of coefficient of correlation matrix is less than 0.3. Table 1 gave the all results of correlation coefficient between each variable. We can see that they are more than 0.3 , having a strong correlation. Therefore they are suitable for factor analysis.

Figure 2 is Changchun rail transfer center data analysis factor scree plot. The scree plot choose the main components mainly through the inflection point. The vertical axis is the eigenvalue, the horizontal axis is the component number. The smaller of eigenvalue, contribution rate of the original variable is smaller. We obtain that in Changchun rail transfer center, numbers of ticket windows and check-in path in component 1 has the maximum contribution rate, The result is provided in Table 2.

The eigenvalues of the first principal component is 9.483 which is shown in Table 3.

The coefficients of the first principal component is as follow:

$(0.983,0.984,0.962,0.905,0.995,0.996,0.998,0.962,0.989,0.959)$.

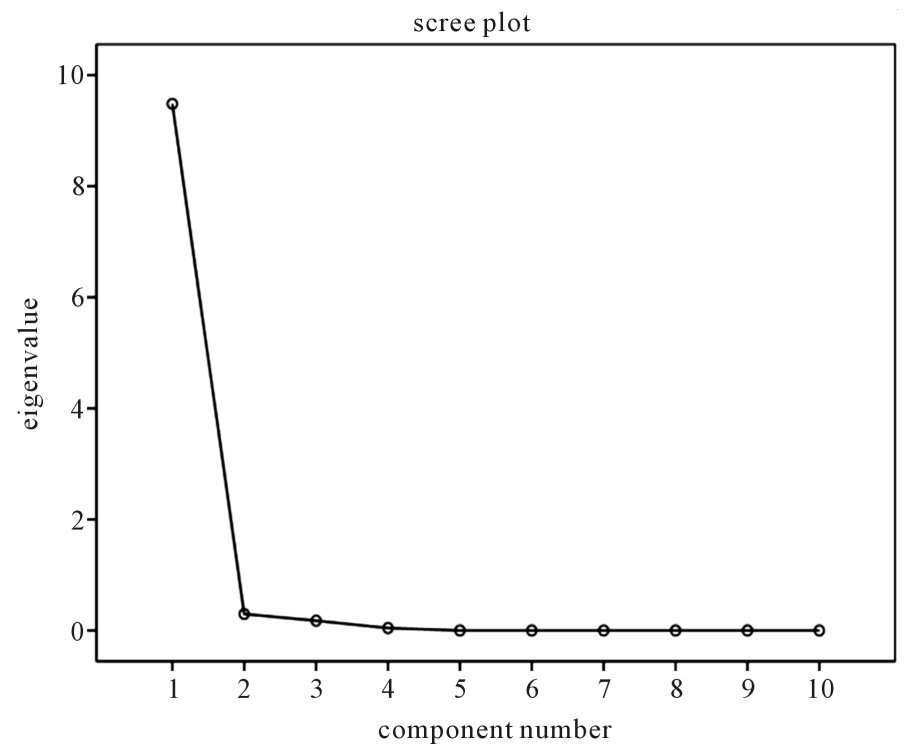

Figure 2. Scree plot in Changchun rail transfer center. 
Table 2. Component matrix of Changchun rail transfer center data.

\begin{tabular}{|c|c|}
\hline \multicolumn{2}{|l|}{ Component matrix ${ }^{\mathrm{a}}$} \\
\hline & Component \\
\hline & 1 \\
\hline Transfer station environment & 0.983 \\
\hline Lighting and the heating system in transfer station & 0.984 \\
\hline Escalator, chairs and trash can in transfer station & 0.962 \\
\hline Crowded degree in transfer station & 0.905 \\
\hline Security facilities in transfer station & 0.995 \\
\hline Pull in and out station time & 0.996 \\
\hline Number of vehicles shifts per day & 0.962 \\
\hline Numbers of ticket windows and check-in path & 0.998 \\
\hline Information provided by transfer station & 0.989 \\
\hline Service attitude of the station staff & 0.959 \\
\hline
\end{tabular}

Extraction method: principal component; ${ }^{\mathrm{a}}$ The components 1 have been extracted.

Table 3. Changchun rail transfer center data to explain factor variance.

\begin{tabular}{cccc}
\hline & \multicolumn{3}{c}{ The total variance explained } \\
\hline \multirow{2}{*}{ Ingredients } & \multicolumn{3}{c}{ Square of extraction and load } \\
\cline { 2 - 4 } & Total & $\%$ of the variance & Cumulative\% \\
\hline 1 & 9.483 & 94.832 & 94.832 \\
\hline
\end{tabular}

Extraction method: principal component analysis.

After dividing $\sqrt{9.483}$ we obtain

$(0.3192,0.3195,0.3124,0.2939,0.3231,0.3234,0.3241,0.3124,0.3212,0.3114)$.

Component 1 in Table 2 is the sum of each factor times corresponding coefficient, that is

$$
\begin{aligned}
\text { Component } 1= & 0.3192 A_{1}+0.3195 A_{2}+0.3124 A_{3}+0.2939 A_{4}+0.3231 A_{5}+0.3234 A_{6} \\
& +0.3241 A_{7}+0.3124 A_{8}+0.3212 A_{9}+0.3114 A_{10} .
\end{aligned}
$$

We get the component score is as follow

$$
(0.104,0.104,0.101,0.095,0.105,0.105,0.105,0.101,0.104,0.101) \text {. }
$$

Obviously, the highest scores are "Security facilities in transfer station", "Pull in and out station time" and "Number of vehicles shifts per day", 0.105, the lowesr score is "Crowded degree in transfer station", 0.095.

We also obtain that in Linhe Street transfer station, "Service attitude of the station staff" in component 1 with the largest eigenvalue has the maximum contribution rate.

\subsection{Comparative Analysis of Satisfaction and Importance}

We analyzed comfort satisfaction of facilities in the rail transfer stations in Changchun, and used analytic hierarchy method to get higher score of satisfaction according to the first questionnaire in July 2014, see Zhou (2015). In order to do comparative analysis, in the second questionnaire we added to the questions of the facility comfort importance. So we obtained the data of comfort importance and got their scores by using the method as follow. 
We use $N_{1}, N_{2}, N_{3}, N_{4}, N_{5}$ to denote the five important degree of each variable, that is most unimportant, unimportant, general, important and very important. Let

$$
N=N_{1}+N_{2}+N_{3}+N_{4}+N_{5} .
$$

Counting $N_{1}, N_{2}, N_{3}, N_{4}, N_{5}$ and calculate the proportion of each number compare with total number $P R_{i}=\frac{N_{i}}{N}(i=1,2,3,4,5)$, we can get the importance of each variable by using the proportion to multiply the weight of important degree

$$
H=\left(H_{1}, H_{2}, H_{3}, H_{4}, H_{5}\right)=(1,2,3,4,5) \text {. }
$$

The formula is as follows:

$$
P R_{i} \cdot H^{\mathrm{T}}=\left(P R_{1}, P R_{2}, P R_{3}, P R_{4}, P R_{5}\right)\left(\begin{array}{l}
H_{1} \\
H_{2} \\
H_{3} \\
H_{4} \\
H_{5}
\end{array}\right)=P R_{1}+2 \times P R_{2}+3 \times P R_{3}+4 \times P R_{4}+5 \times P R_{5} .
$$

We can get the importance degree of each variable from 475 questionnaire survey which is shown as Table 4 .

Through the comparative analysis of satisfaction and importance, we choose three typical questions to analyze specifically. They are "Security facilities in transfer station" (Abbreviated "Security"), "Crowded degree in transfer station" ("Crowded degree") and "Information provided by transfer station" ("Information"). The average scores of importance of these three questions in of rail transit transfer stations in Changchun are 4.2274, 4.1200 and 4.1832, see Table 4. The average scores of satisfaction are 3.6929, 3.4568 and 3.7157, see Table 5 in section 5.

Figure 3, Figure 4 and Figure 5 showed the broken line graphs of importance of the three variables, "Security", "Crowded degree" and "Information". The horizontal axis is the score of importance. The vertical axis is the number of people in each score.

"Security" has the highest score of importance in the all questions, 4.2274, and its score of satisfaction comparing to others is also higher, 3.6929. With the increase of urban population and traffic congestion, rail transportation has been becoming a first choice by the transport. Rail transit transfer stations are the places where

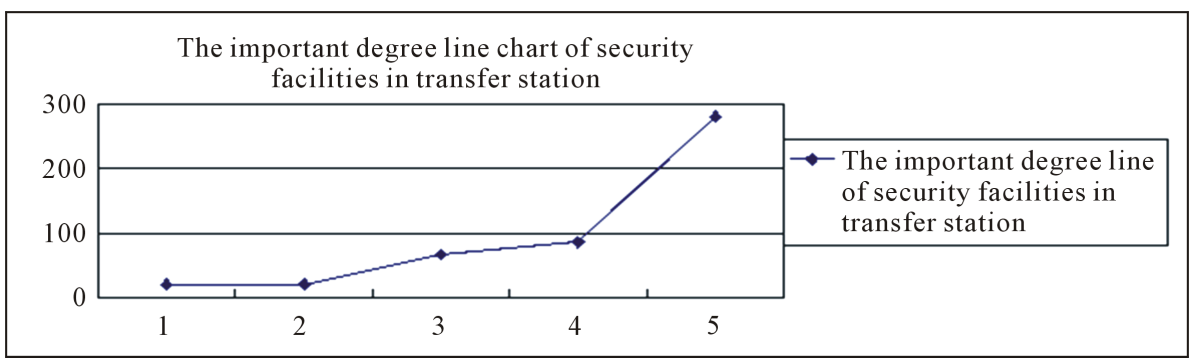

Figure 3. Broken line graph of importance of security.

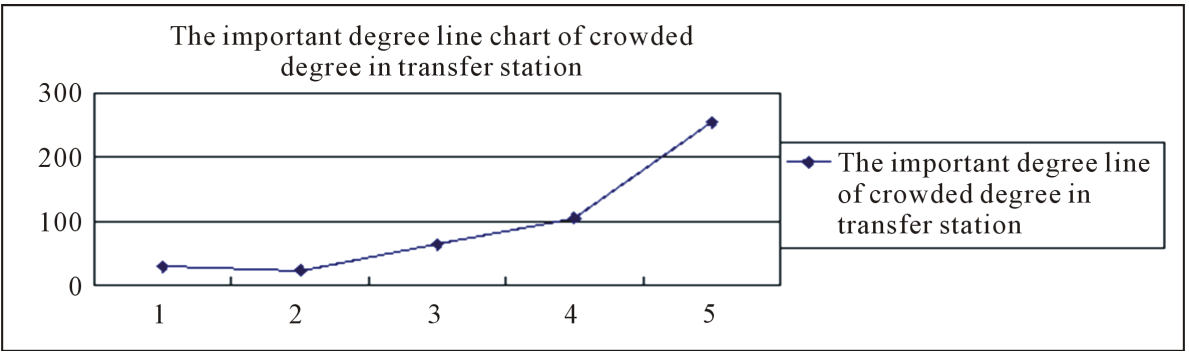

Figure 4. Broken line graph of importance of crowded degree. 


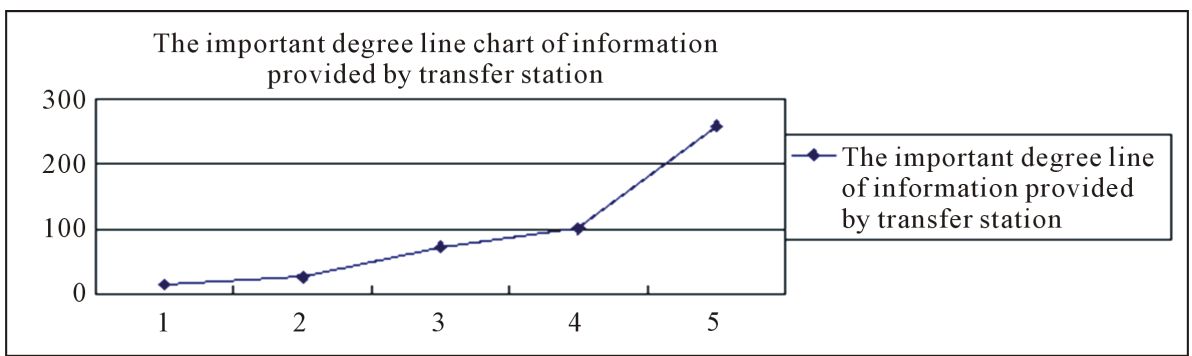

Figure 5. Broken line graph of importance of information.

Table 4. The importance degree of each variable from 475 questionnaire survey.

\begin{tabular}{ccccccccccc}
\hline$A_{1}$ & $A_{2}$ & $A_{3}$ & $A_{4}$ & $A_{5}$ & $A_{6}$ & $A_{7}$ & $A_{8}$ & $A_{9}$ & $A_{10}$ \\
\hline 4.0968 & 4.1347 & 4.1432 & 4.1200 & 4.2274 & 4.0189 & 4.5254 & 4.0842 & 4.1832 & 4.1453 \\
\hline
\end{tabular}

Table 5. Satisfaction scores in rail transit transfer stations in Changchun.

\begin{tabular}{|c|c|c|c|c|c|c|c|}
\hline Factor & Weight & $\begin{array}{c}\text { Quite } \\
\text { unsatisfactory }\end{array}$ & Unsatisfactory & General & Satisfactory & $\begin{array}{c}\text { Very } \\
\text { satisfactory }\end{array}$ & Mean \\
\hline Efficiency & 0.1143 & 0.0614 & 0.0557 & 0.2176 & 0.3445 & 0.3208 & 3.8076 \\
\hline Pull in and out station time & 0.2941 & 0.0673 & 0.0884 & 0.2295 & 0.3074 & 0.3074 & 3.6992 \\
\hline Number of vehicles shifts per day & 0.7059 & 0.0590 & 0.0421 & 0.2126 & 0.3600 & 0.3263 & 3.8525 \\
\hline Convenience & 0.2196 & 0.0800 & 0.0800 & 0.2337 & 0.2968 & 0.3095 & 3.6758 \\
\hline $\begin{array}{l}\text { Numbers of ticket windows and } \\
\text { check-in path }\end{array}$ & 1 & 0.0800 & 0.0800 & 0.2337 & 0.2968 & 0.3095 & 3.6758 \\
\hline Comfort & 0.2723 & 0.0962 & 0.0993 & 0.2575 & 0.2782 & 0.2688 & 3.5241 \\
\hline Transfer station environment & 0.1667 & 0.0653 & 0.0737 & 0.2758 & 0.3221 & 0.2631 & 3.644 \\
\hline $\begin{array}{l}\text { Lighting and the heating system in } \\
\text { transfer station }\end{array}$ & 0.1667 & 0.0821 & 0.1137 & 0.2232 & 0.3158 & 0.2652 & 3.5683 \\
\hline $\begin{array}{l}\text { Escalator, chairs and trash can in } \\
\text { transfer station }\end{array}$ & 0.1667 & 0.0758 & 0.0989 & 0.2758 & 0.2863 & 0.2632 & 3.5622 \\
\hline Crowded degree in transfer station & 0.4999 & 0.1179 & 0.1032 & 0.2568 & 0.2484 & 0.2737 & 3.4568 \\
\hline Safety & 0.3136 & 0.0568 & 0.0926 & 0.2505 & 0.3011 & 0.2990 & 3.6929 \\
\hline $\begin{array}{l}\text { Security facilities in transfer } \\
\text { station }\end{array}$ & 1 & 0.0568 & 0.0926 & 0.2505 & 0.3011 & 0.2990 & 3.6929 \\
\hline Service & 0.0802 & 0.0668 & 0.0670 & 0.2310 & 0.3011 & 0.3341 & 3.7687 \\
\hline $\begin{array}{l}\text { Information provided by } \\
\text { transfer station }\end{array}$ & 0.4286 & 0.0632 & 0.0779 & 0.2526 & 0.2926 & 0.3137 & 3.7157 \\
\hline Service attitude of the station staff & 0.5714 & 0.0695 & 0.0589 & 0.2147 & 0.3074 & 0.3495 & 3.8085 \\
\hline$\Sigma$ & 1 & 0.0740 & 0.0853 & 0.2434 & 0.2989 & 0.2984 & 3.6624 \\
\hline
\end{tabular}

large pedestrian flow. So its security gets the government and passengers more and more attention. On the other hand, reasonable allocation of safety facilities in rail transit transfer station has also contributed to the people's choices of rail transit.

"Crowded degree" has the higher importance score, and the lowest satisfaction score. This result explains the gap of reality and passengers expectations. With the social progress and economic development, convenient and fast become the main choice, so rail transportation became passengers main travel way. Crowded degree in rail 
transit transfer stations also became a problem people pay attention to. In addition, rail transit transfer station is the site passengers travel on transportation. The pedestrian within the transfer station have higher density. Crowded conditions can effect the traveler satisfaction. So "crowded degree" is the lowest.

The satisfaction and importance scores of "Information" are both higher. On one hand, rail transit transfer station information can help people better and faster choosing transportation routes, saving time and easy to understand. On the other hand, detailed and accurate information is further standardized of rail transfer station facilities. The more information gets higher satisfaction score.

\section{The Satisfaction Results in Changchun}

In this section, we used analytic hierarchy method to analyze the satisfaction of facilities in rail transit transfer stations, including Changchun rail transfer center and Linhe Street transfer station. Facilities satisfaction scores are shown in Table 5.

In Table 5, the score of Comfortable satisfaction is 3.5241, less then the scores of general and satisfactory. Its degree of membership is 0.7048 (3.5241/5). The comfortable degree of satisfaction in Changchun rail transit transfer station facilities is $70.48 \%$. Using the same method we can calculated the degrees of efficiency, convenience, safety, and service satisfaction, $76.15 \%, 73.52 \%, 73,86 \%, 73.37 \%$, respectively.

\section{Some Suggestions}

From the results in Table 5, we can see that the overall level of satisfaction in Changchun rail transit transfer Station is higher. The highest score is "Number of vehicles shifts per day", 3.8525. The second is "Service attitude of the station staff”, 3.8085. They belong to Efficiency and Service. But Comfortable has a lowest score in the five rule layer, "Crowded degree", "Lighting and the heating system", "Escalator, chairs and trash can" in transfer station are still a lot of problems. So it is recommended that the Changchun rail transfer station should take some measures to solve these problems. It may be appropriate to improve the scale of rail transfer stations, increase the number of escalator, and improve the exit width. If these facilities improved, comfortable satisfaction of people in Changchun will increase and the attractive of Changchun rail transit transfer stations will increase.

\section{Acknowledgements}

This work was support by NSF grant 51278221 and grant 51378076 from the National Natural Science Funds in China and Collage innovation projects in China: 40103-129645.

\section{References}

[1] Fornell, C., Johnson, M.D., Snderson, E.W., Cha, J. and Bryant, B.E. (1996) The American Customer Satisfaction Index; Nature, Purpose and Findings. Journal of Marketing, 60, 7-18. http://dx.doi.org/10.2307/1251898

[2] Giese, J.L. and Cote, J.A. (2000) Defining Consumer Satisfaction. Academy of Marketing Science Review, 1, 1-27.

[3] Smith, A.K., Bolton, R.N. and Wagner, J. (1999) A Model of Customer Satisfaction with Service Encounters Involving Failure and Recovery. Journal of Marketing Research, 36, 356-372. http://dx.doi.org/10.2307/3152082

[4] Morgan, N.J., et al. (1996) The Role of Product/Service Experience in the Satisfaction Formation Process: A Test of Moderation. Journal of Consumer Satisfaction, 9, 391-405.

[5] Kretz, T. (2007) Pedestrian Traffic: Simulation and Experiments. Ph.D. Thesis, Faculty of Physics, University of Duisburg, Essen.

[6] Dannmen, W. (2004) Modelling Passenger Flows in Public Transport Facilities. Delft University of Technology, Delft.

[7] Kenneth, W. (2004) Building Type Basics for Transit Facilities. John Wiley \& Sons, Hoboken.

[8] Xu, Y.J. (2009) The Methods of Social Investigation and Research of. Online Document. http://www/comp.nus.edu.sg

[9] Zhou, C.S., et al. (2015) Investigation and Analysis of Satisfaction of City Rail Transfer Station Facilities in Changchun. Journal of Changchun University of Science and Technology, 2, 158-162. 